\title{
Vertical Shifts in Self-Administration Dose-Response Functions Predict a Drug-Vulnerable Phenotype Predisposed to Addiction
}

\author{
Pier Vincenzo Piazza, Véronique Deroche-Gamonent, Françoise Rouge-Pont, and Michel Le Moal \\ Laboratoire de Psychobiologie des Comportements Adaptatifs, Domaine de Carreire, 33077 Bordeaux, France
}

The role of individual differences in the etiology of addiction is a very controversial issue. Neuroendocrine phenotypes that are able to predispose an individual to the development of drug intake have been identified previously. However, such information has been gathered by comparing individuals who differ in their sensitivity to low doses of the drug. Consequently, it remains unclear whether a phenotype predicting a higher sensitivity to low drug doses would be relevant in environmental conditions, such as the ones encountered by humans in which high drug doses are available. In this report, we studied doseresponse, dose-intake, and ratio-intake functions for intravenous cocaine self-administration in the laboratory rat. We show that individual differences in drug self-administration originate from vertical shift in the dose-response function. Thus, no matter the dose, drug intake is very high in some "vulnerable" subjects and very low in other "resistant" ones. Vulnerable subjects, the upward shifted ones, would then have a higher chance to develop drug abuse also when high drug doses are available. In conclusion, these results provide a solid foundation for the existence of a drug-vulnerable phenotype relevant for the etiology of addiction.

Key words: drug abuse; predisposition; individual differences; cocaine; intravenous self-administration; dose-response; progressive ratio; upward shifts; drugs of abuse
An important issue in the field of drug abuse is to understand whether there exists a "vulnerable" phenotype that predisposes one to addiction (O'Brien et al., 1986; Piazza and Le Moal, 1996). Individual differences in the responses to drugs of abuse have been widely demonstrated in humans (De Wit et al., 1986; O'Brien et al., 1986; Crowley et al., 1998) and laboratory animals (Crabbe et al., 1994; Piazza and Le Moal, 1996). For example, when providing rodents with low unitary doses of drugs, only some more sensitive individuals develop intravenous drug selfadministration (Piazza et al., 1989), the principal model of drug abuse. Self-administration-prone subjects can be identified because of their behavioral reactivity to a stress challenge, such as the forced exposure to a novel environment (Piazza et al., 1989). Animals with a high locomotor response to novelty, defined as high responders (HR) compared with low responder animals (LR), show the highest sensitivity to drugs (Piazza et al., 1989; Piazza and Le Moal, 1996).

Although the existence of individual differences in the behavioral responses to drugs is widely accepted, their relevance to the etiology of addiction remains very controversial (Altman et al., 1996), the principal criticism being that such individual difference in drug responses would have no practical influence on the development of addiction in environmental conditions, such as the "real world" in which large amounts of drugs are available. This criticism is justified by the fact that variations in drug responses are currently interpreted as horizontal shifts in self-administration

Received Jan. 13, 2000; revised March 6, 2000; accepted March 10, 2000.

This work was supported by grants from Institut National de la Santé et de la Recherche Médicale, University of Bordeaux II. We thank the following individuals for their comments and discussions on the data and the concepts contained in this report: A. Badiani, S. Cabib, T. Robinson, J. Stewart, and R. A. Wise.

Correspondence should be addressed to Pier Vincenzo Piazza, Laboratoire de Psychobiologie des Comportements Adaptatifs, Institut National de la Santé et de la Recherche Médicale U259, Université de Bordeaux II, Domaine de Carreire, Rue Camille Saint-Saëns, 33077 Bordeaux cedex, France. E-mail: piervincenzo.piazza@bordeaux.inserm.fr.

Copyright (C) 2000 Society for Neuroscience $0270-6474 / 00 / 204226-07 \$ 15.00 / 0$ dose-response functions, i.e., differences in the sensitivity to experience drug effects (Koob et al., 1986; Deminière et al., 1989; Wise 1996).

Figure 1 shows a typical self-administration dose-response function. $^{a}$ According to the model of horizontal shifts (Koob et al., 1986; Deminière et al., 1989; Wise, 1996), vulnerable subjects are the most sensitive, i.e., the ones leftward shifted, and these individuals would develop self-administration at low unitary doses of the drug (see Fig. 1B, top). However, at higher doses, "resistant" subjects, which are the less sensitive and rightward shifted, would provide an equal rate of self-administration (see Fig. $1 B$, top) and even take the highest quantity of the drug (see Fig. $1 B$, middle). Consequently, when both low and high drug doses are available, horizontal shifts predict that individual differences do not influence the development of drug abuse. Although horizontal shifts in drug self-administration constitute the framework currently used to interpret self-administration data, a widely ignored alternative exists, i.e., dose-response functions could be vertically shifted. Vertical shifts (see Fig. 1C) predict a totally different vulnerable phenotype. In this case, vulnerable subjects, which are the upward shifted ones, present a higher rate of responding across doses (see Fig. 1C, top) and consume the highest quantities of the drug (Fig. 1C, middle). Consequently, these vulnerable individuals would have the highest chances to

\footnotetext{
$\overline{{ }^{a} \text { Self-administration dose-response functions are typically bell-shaped and are }}$ obtained by training animals at a high unitary dose of the drug. Once the behavior is acquired and stabilized, the dose is progressively varied between sessions. Similar bell-shaped curves are obtained if the dose is progressively decreased or changed randomly. Within a certain range of doses, such as right (or descending) limb of the dose-response function, the animal will react to the decrease in dose by increasing responding (see Fig. 1A, top). As a result, for doses that are in the right limb of the dose-response function, drug intake remains fairly constant (see Fig. 1A, bottom). This phenomenon is interpreted as an attempt to compensate for the decrease in the unitary dose and maintain an ideal level of reinforcement. However, below a certain level of unitary drug doses, such as left (or ascending) limb of the dose-response function, responding progressively decreases, and this is probably because the dose of the drug is too low to efficiently maintain responding.
} 


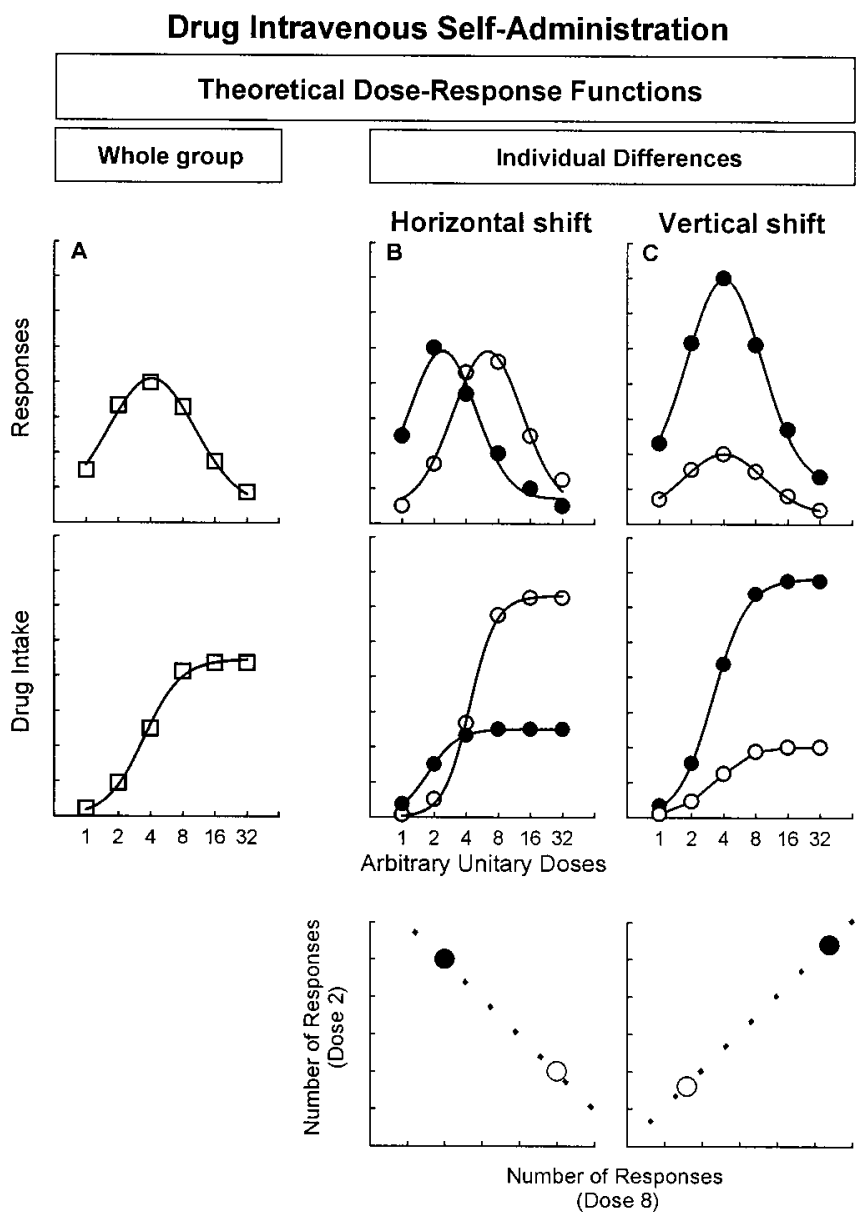

Figure 1. Classical intravenous self-administration dose-response and dose-intake functions $(A)$ and theoretical expression of individual differences as horizontal $(B)$ or vertical $(C)$ shifts of these functions. The two models predict two different drug-vulnerable (filled circles) and drugresistant (open circles) phenotypes. In the case of a horizontal shift, a vulnerable subject (the one leftward shifted) will have a higher number of responses $(B$, top $)$ in the active device (the ones delivering the drug) only for low unitary drug doses. In the case of a vertical shift $(C$, top), a vulnerable subject (the one upward shifted) will have higher responses in the active device across doses. As a consequence, the leftward shifted individuals will have the lowest drug intake $(B$, middle), whereas the upward shifted subjects will have the highest one $(C$, middle). Furthermore, taking into account all of the subjects, the correlation between the number of responses in the active device at doses in the ascending (for example, the 2 dose) and descending (for example, the 8 dose) limbs of the dose-response function will be negative if a horizontal shift $(B$, bottom $)$ occurs and positive in the case of a vertical one $(C$, bottom $)$.

develop drug abuse also in environmental conditions in which both low and high drug doses are available.

In this report, we have studied dose-response, dose-intake, and ratio-intake functions for intravenous cocaine selfadministration in the laboratory rat. It was found that individual differences in drug self-administration originate from vertical shifts in dose-response functions. Vulnerability to drugs appears independent of dose in that no matter what the dose, drug intake is very high in certain vulnerable subjects and very low in other resistant ones. Consequently, vulnerable subjects would have a higher chance to develop addiction independent of the quantity of drugs available in the real world.

\section{MATERIALS AND METHODS}

\section{General methods}

Animals and surgical procedures. Sprague Dawley rats (280-320 gm; Iffa-Credo, Lyon, France) were individually housed under a constant 12 hr light/dark cycle (on at 12:00 A.M., off at 12:00 P.M.) with ad libitum access to food and water. Under ether anesthesia, a SILASTIC catheter (12 $\mu$ l dead volume) was inserted in the right auricle through the external jugular vein. The catheter was then passed under the skin and fixed in the midscapular region. For the first $3 \mathrm{~d}$ after surgery, the catheters were flushed daily with $0.1 \mathrm{ml}$ of saline mixed with heparin $(100 \mathrm{U} / \mathrm{ml})$ and gentamicin $(1 \mathrm{mg} / \mathrm{kg})$. Thereafter, the catheters were flushed with a saline-heparin mixture after each saline session.

Drugs. Cocaine $\mathrm{HCl}$ (Coopération Pharmaceutique Française, Bordeaux, France) was dissolved in $\mathrm{NaCl} 0.9 \%$.

Locomotor response to novelty. The novel environment was a circular corridor $(10 \mathrm{~cm}$ wide and $70 \mathrm{~cm}$ in diameter). Four photoelectric cells placed at the perpendicular axis of the apparatus automatically recorded locomotion. Individual responses were measured after a $7 \mathrm{~d}$ period of habituation to the housing conditions and before any other manipulation. As described previously (Piazza et al., 1989), animals were divided into high and low responders to novelty on the basis of their activity scores accumulated over $2 \mathrm{hr}$. The HR group contained animals with activity scores above the median of the whole group; the LR group contained all of the other animals.

Intravenous self-administration. The procedure and the equipment for self-administration were identical to the ones described previously (Deroche et al., 1997). Each self-administration chamber $(35 \times 33 \mathrm{~cm}$ floor area, $50 \mathrm{~cm}$ high) was provided with two holes in the middle of each of the larger sides at $5 \mathrm{~cm}$ from the floor of the cage. By introducing their nose (nose-poke) into one of the holes, defined as active, rats triggered a photocell, activated a syringe pump, and initiated an infusion of $20 \mu \mathrm{l}$ of cocaine solution over $2 \mathrm{sec}$. Each infusion was followed by a $20 \mathrm{sec}$ time-out period during which further nose-pokes were recorded but did not result in additional intravenous infusions. A nose-poke in the other hole, defined as inactive, was without scheduled consequences at any time. The number of responses at both holes and the number of reinforcements earned (number of infusions) were recorded for the entire session. The number of responses is usually higher than the number of inf usions because of responding during the time-out period.

Cocaine assay. Brain content of cocaine in HR and LR animals was measured by HPLC with UV detection as described previously (Marinelli et al., 1997). Animals were killed by decapitation, and the brains were quickly frozen. Results were expressed as micrograms per gram of brain tissue.

Statistical analysis. Results were analyzed using ANOVA (Crunch statistical package) for repeated measures. The groups (HI/LI or $\mathrm{HR} / \mathrm{LR}$ animals) were used as between factors. The dose (six levels) or the ratio (six levels) was used as within factors. Correlations were evaluated by the Pearson's correlation test.

\section{PROCEDURES}

Experiment 1: study of individual differences in dose-response, dose-intake, and ratio-response functions

Self-administration procedures. Six days after catheter implantation, animals $(n=18)$ were trained to self-administer cocaine at $1 \mathrm{mg} / \mathrm{kg}$ per infusion, which in our experimental conditions corresponds to the $\mathrm{ED}_{100}$ (efficacious dose) of this behavior. The $\mathrm{ED}_{100}$ was defined as the dose at which the percentage of animals that acquired the behavior was close to $100 \%$. Self-administration sessions (one per day, $1 \mathrm{hr}$ each) were conducted between 1:00 and 6:00 P.M. using a fixed ratio (FR) 1 (one response per infusion) schedule. After $10 \mathrm{~d}$ of training, the dose of the drug was progressively decreased between sessions, each dose being maintained at least for $3 \mathrm{~d}$ and until the responding of the animal was stable $(<10 \%$ variation) over $2 \mathrm{~d}$. For the lower doses of cocaine, this criteria was reached after 5-7 d. The $E_{50}$ for cocaine selfadministration was calculated with respect to the dose-intake function and corresponded to the dose at which half of the maximal intake was observed. Once the dose-response function was completed, animals were stabilized again at $1 \mathrm{mg} / \mathrm{kg}$ per infusion, but this time an FR6 (six responses per infusion) schedule was applied. Next, a ratio-response function was performed by maintaining constant the dose and increasing the number of responses (ratio) necessary to obtain one infusion. This procedure measured the intensity of cocaine, reinforcing effects by evaluating the number of responses that the animals provided to obtain one 
Cocaine Intravenous Self-Administration

Figure 2. Experimentally observed dose-response and dose-intake functions for intravenous selfadministration of cocaine represented as the following: means \pm SE for the entire group of animals $(A)$; individual values $(B)$; separate means \pm SE for animals with a high and low intake of cocaine at the highest dose (1 mg/kg per inf usion) (C, top, middle); and correlation between the number of responses (nose-pokes) in the active device for doses of the ascending $(0.06 \mathrm{mg} / \mathrm{kg}$ per infusion $)$ and descending $(0.25 \mathrm{mg} / \mathrm{kg}$ per infusion) limbs of the doseresponse function $(C$, bottom $)$. There were large individual differences in the number of responses (nose-pokes) in the active device (the ones delivering a drug infusion) $(B$, top $)$ and cocaine intake $(B$, bottom). These differences were derived by vertical shifts in individual dose-response functions. Thus, HI animals compared with LI animals showed upward shifted dose-response $(C, t o p)$ and doseintake $(C$, bottom) functions that did not differ for the $\mathrm{ED}_{50}$ (as calculated on the dose-intake function). Furthermore, the number of responses in the ascending and descending limbs of the doseresponse function were positively correlated $(C$, bottom). The individual values used for computing the graphs were the mean of the last $2 \mathrm{~d}$ of testing at each dose.

\section{Observed Dose-Response Functions}
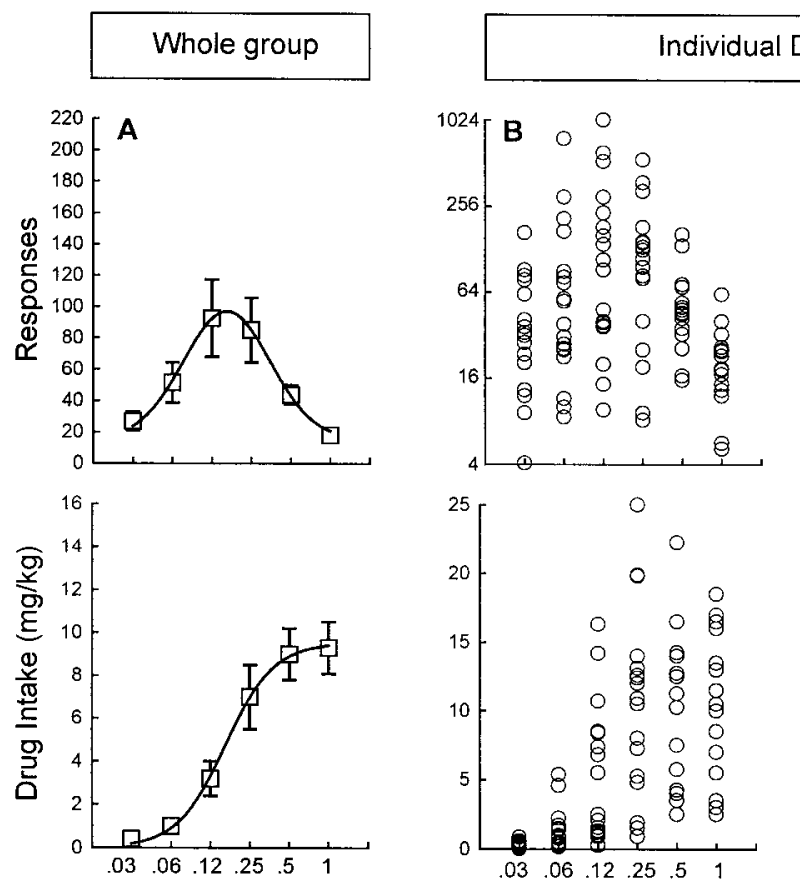

Unitary Doses (mg/kg/inf.)

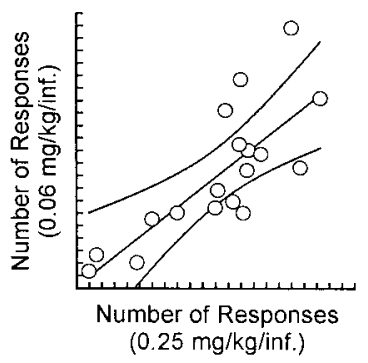

infusion of the drug. The ratio was progressively increased every two sessions up to FR54. Each session started with the assigned ratio that remained stable within one session.

Study of individual differences. The occurrence of either vertical or horizontal shifts in dose-response functions between individuals can be determined on the basis of two parameters that produce opposite results depending on the shift that occurs. (1) The first parameter is the amount of drug intake at high unitary doses. Animals with the highest drug intake will be the less sensitive (rightward shifted) in the case of a horizontal shift (Fig. 1B, middle) and the most vulnerable (upward shifted) in the case of a vertical shift (Fig. 1C, middle). To study this parameter animals were divided into two groups on the basis of their intake at the highest unitary dose of cocaine studied ( $1 \mathrm{mg} / \mathrm{kg}$ per infusion). The high intake (HI) group contained all of the animals with an intake above the median of the whole group. The low intake (LI) group contained all of the other animals. (2) The second parameter is the correlation between the number of responses in the ascending and descending limbs of the doseresponse function. For a whole group of animals, this correlation will be negative in the case of a horizontal shift (Fig. $1 B$, bottom) and positive in the case of a vertical shift (Fig. 1C, bottom). Thus, in the case of an horizontal shift, subjects (Fig. 1B, filled circles) with the lower number of responses in the active device at high unitary doses (for example, hypothetical dose 8 in Fig. 1) will have the higher number of responses at low unitary doses (for example, the hypothetical dose 2 in Fig. 1). Conversely, in the case of a vertical shift, the subjects (Fig. 1C, filled circles) with the higher number of responses at high unitary doses (for example, hypothetical dose 8) will also have the higher number of responses at low ones (for example, hypothetical dose 2). The nature of this relationship was assessed by analyzing the correlation between the number of responses in the active hole at different doses.

\section{Experiment 2: relationships between acquisition threshold and dose-response functions for cocaine self-administration}

In a second experiment, we determined whether an upward shift in the self-administration dose-response function corresponds to a higher propensity to develop cocaine self-administration at low doses of the drug. For this purpose, we compared high and low responders to novelty $(n=$ 7 per group and per condition). Thus, it has been shown previously that these groups of animals differ for the acquisition of self-administration of low doses of amphetamine (Piazza et al., 1989). In two independent groups of animals, the acquisition of self-administration at a low dose of cocaine $(0.1 \mathrm{mg} /$ infusion $)$ and a full dose-response function $(1 \mathrm{mg} / \mathrm{kg}$ per infusion was the training dose) were studied. Self-administration procedures were identical to the ones described above. Briefly, animals were first tested for their locomotor response to novelty and than implanted with the intravenous catheter. After $6 \mathrm{~d}$ of recovery, they were trained to self-administer cocaine on an FR1 schedule. Animals received one self-administration session per day for 7 consecutive days. Sessions lasted $1 \mathrm{hr}$ and were conducted between 1:00 and 6:00 P.M. These procedures were also used for the dose-response function. This time animals were trained with $1 \mathrm{mg} / \mathrm{kg}$ per infusion and the training at this dose lasted $10 \mathrm{~d}$. After this period, the dose was progressively reduced between sessions. Each dose was maintained for at least $3 \mathrm{~d}$ and until the response of the animals was stable over $2 \mathrm{~d}$ ( $<10 \%$ variation). 


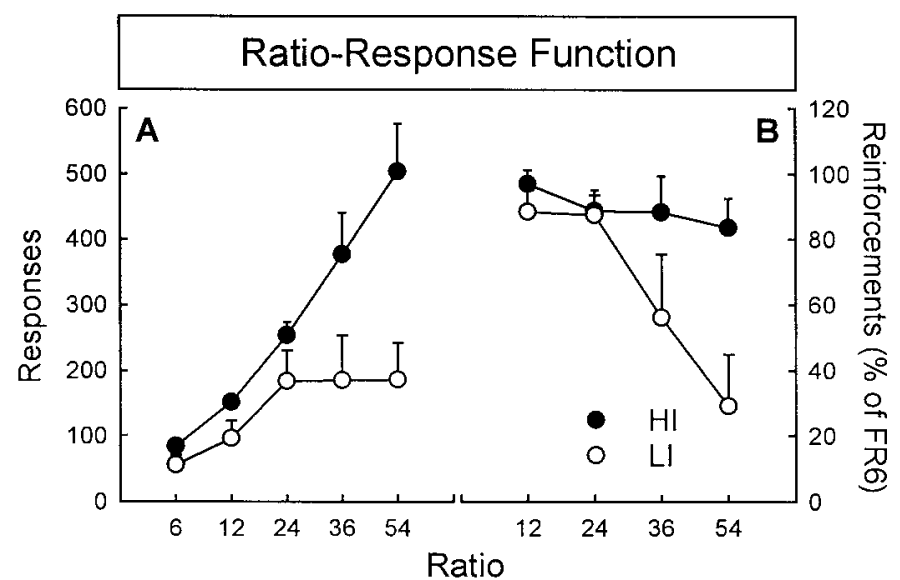

Figure 3. Ratio-response function for cocaine intravenous selfadministration in animals with high and low cocaine intake. Results are expressed as number of responses $(A)$ and reinforcements (number of infusions) earned $(B)$ over ratios. HI animals reacted at the increase in ratio (the response requirement necessary to obtain one drug infusion) with a proportional increase in responding, whereas, after FR24 (24 responses for one infusion), responding did not increase any more in LI animals. As a consequence, the intake of cocaine remained stable for HI but rapidly decreased in LI at the increase in ratio.

\section{Experiment 3: differences between $H R$ and LR animals in} brain levels of cocaine

On the basis of the results of the previous experiments revealing significant differences between HR and LR animals in cocaine selfadministration, in a third experiment, we studied the pharmacokinetics of cocaine. The aim of this experiment was to establish whether the behavioral differences observed could depend on differences in the bioavailability of the drug. For this purpose, independent groups of HR and LR rats were implanted with an intravenous catheter, left to recover for 1 week, and infused with $2 \mathrm{mg} / \mathrm{kg}$ cocaine, which corresponds to the average loading dose observed during cocaine self-administration. Animals in HR and LR groups were then killed 2, 10, and 20 min after the inf usion of cocaine ( $n=8$ per group and per time point).

\section{EXPERIMENT RESULTS}

\section{Experiment 1: individual differences in cocaine self- administration dose-response functions}

In our experimental conditions, a typical bell-shaped doseresponse function for cocaine self-administration was observed (Fig. 2A). Individual differences in this behavior were very large, as shown in Figure $2 B$ in which the number of responses (nosepokes) in the active device (Fig. $2 B$, top) and cocaine intake (Fig. $2 B$, bottom) for each individual are depicted. Comparisons of groups constituted on the basis of the intake at the highest dose ( $1 \mathrm{mg} / \mathrm{kg}$ per infusion) and correlation between the number of responses at the different doses indicate that individual difference in this behavior depend on vertical shifts in dose-response functions. Indeed, these two parameters predict opposite results depending on the shift occurring (Fig. 1). In the case of a vertical shift, (Fig. 1C) animals with an HI (Fig. 1C, middle) should have a dose-response function shifted upward (Fig. 1C, top), and a positive correlation should be found between the number of responses in the ascending and descending limbs of the doseresponse function (Fig. $1 C$, bottom). In the case of a horizontal shift, HI animals (Fig. 1B, middle) should have a dose-response function shifted toward the right (Fig. $1 B$, top), and a negative correlation should be found between the number of responses in the ascending and descending limbs of the dose-response function (Fig. 1B, bottom).

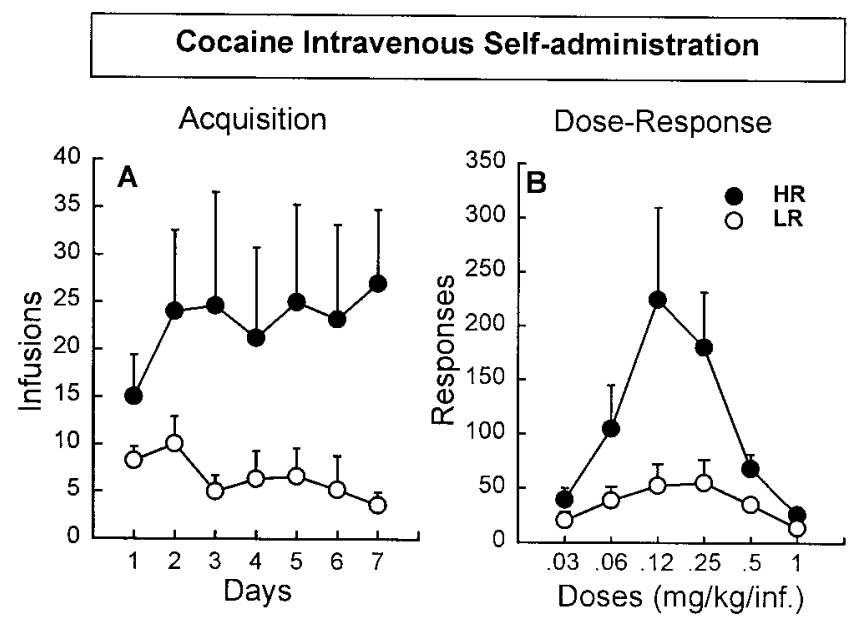

Figure 4. Cocaine intravenous self-administration acquisition $(A)$ and dose-response function $(B)$ in high and low responders to novelty. HRs compared with LRs were the only group to acquire self-administration for a low dose of cocaine (100 $\mu \mathrm{g}$ /infusion), and their dose-response function was upward shifted.

Figure $2 C$ shows clearly that only the predictions provided by the model of vertical shifts (Fig. 1C) are fulfilled. Thus, animals with an HI compared with animals with an LI had a significant upward shift in the dose-response (Fig. 2C, top) (group effect, $F_{(1,16)}=7.39 ; p<0.01$ ) and dose-intake (Fig. 2C, middle) (group effect, $\left.F_{(1,16)}=10.75 ; p<0.005\right)$ functions. Furthermore, the number of responses in the active device for unitary doses of cocaine in the ascending (0.03-0.12 $\mathrm{mg} / \mathrm{kg}$ per infusion) and descending (0.25-1 $\mathrm{mg} / \mathrm{kg}$ per infusion) limbs of the doseresponse functions were always positively correlated. This is exemplified in the bottom of Figure $2 C$ by the correlation $(r=$ $0.79 ; p<0.01)$ between the number of responses at 0.06 and 0.25 $\mathrm{mg} / \mathrm{kg}$ per inf usion doses. The absence of a significant horizontal shift was also shown by the lack of differences in the $\mathrm{ED}_{50}$ for the HI and LI groups (HI, $0.145 \mathrm{mg} / \mathrm{kg}$ per inf usion; LI, $0.187 \mathrm{mg} / \mathrm{kg}$

\section{Cocaine Brain Levels}

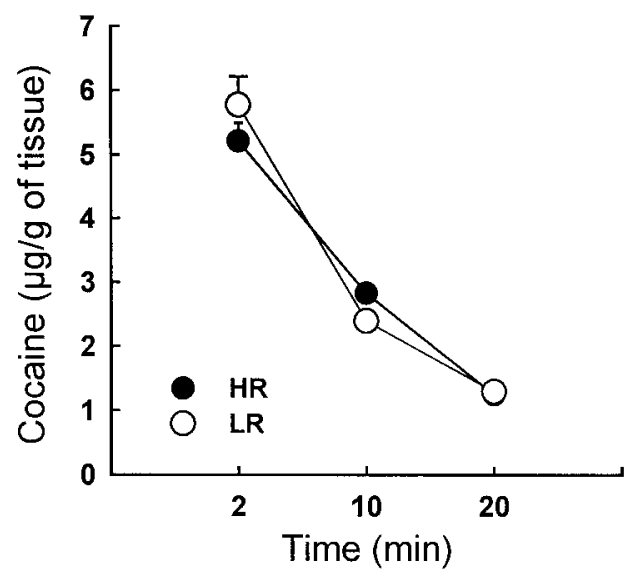

Figure 5. Brain levels of cocaine in HR and LR animals. After the intravenous inf usion of $2 \mathrm{mg} / \mathrm{kg}$ cocaine, the two groups did not differ for brain levels of the drug. Brain levels of cocaine were measured 2, 10, and 20 min after the infusion of the drug. 
per infusion; $p>0.18$ ) and from the lack of interaction between group and dose (group $\times$ dose interaction, $F_{(5,80)}=0.27$; $p>0.92)$.

The results of the ratio-response function indicate that the reinforcing effects of cocaine were higher in animals with an upward shift in the dose-response function. When the ratio requirement (number of responses needed to obtain one infusion) was progressively increased between sessions, HI animals provided a higher number of responses (nose-pokes) in the active device than LI animals (Fig. $3 A)\left(F_{(4,64)}=2.82 ; p<0.035\right)$. The higher increase in responding among the HI animals had two consequences. First, the number of reinforcements (cocaine infusions) earned by HI animals was higher than the ones of LI animals $\left(F_{(3,48)}=5.23 ; p<0.003\right)$. Second, the number of reinforcements earned by $\mathrm{HI}$ animals remained constant at the increase in ratio requirement $\left(F_{(3,24)}=1.21 ; p>0.3\right)$, although it progressively decreased $\left(F_{(3,24)}=9.33 ; p<0.0003\right)$ in LI animals (Fig. $3 B$ ). This result indicates that $\mathrm{HI}$ animals are ready to respond more in the active device than LI animals to maintain a constant intake of cocaine.

HI and LI animals did not differ for basal levels of responding. Thus, in none of the conditions studied did these groups differ in the number of responses (nose-pokes) made in the control device (inactive hole).

\section{Experiment 2: relationships between acquisition threshold and dose-response functions for cocaine self-administration}

HRs and LRs differed in locomotor activity in a novel environment. The activity scores cumulated over $2 \mathrm{hr}$ of exposure to the novel environment were as follows: HR, $1154.07 \pm 53.36$; LR, $677.92 \pm 40.08\left(F_{(1,26)}=50.25 ; p<0.0001\right)$. These differences in locomotion between HR and LR are in the range of the ones reported previously (Piazza et al., 1989; Lucas et al., 1998). High and low responders also differed for cocaine self-administration. When the two groups were tested for the acquisition of cocaine self-administration, at a low unitary dose of the drug, high responders acquired and maintained self-administration, whereas low responders did not, as shown by the significant difference between the two groups in the number of cocaine infusions over days (Fig. $4 A)\left(F_{(1,12)}=9.31 ; p<0.01\right)$. HRs and LRs also differed for cocaine self-administration dose-response function, which was significantly upward shifted (Fig. $4 B$ ) in HRs compared with LRs (group effect, $F_{(1,12)}=6.5 ; p<0.02$ ). However, there was no significant interaction between group and dose $\left(\right.$ group $\times$ dose interaction, $\left.F_{(5,60)}=1.12 ; p>0.35\right)$, nor did HRs and LRs differ in basal levels of responding given that in none of the conditions studied did these groups differ in the number of responses made in the control device (inactive hole). Consequently, the behavioral phenotype showed by the HR and LR groups was similar to that observed respectively in HI and LI animals.

\section{Experiment 3: differences between HR and LR animals in brain levels of cocaine}

Despite the large differences in cocaine-induced behaviors, HR and LR groups did not differ in cocaine bioavailability. Thus, after the intravenous infusion of $2 \mathrm{mg} / \mathrm{kg}$ of cocaine, HRs and LRs had indistinguishable brain levels of the drug (Fig. 5) $\left(F_{(1,42)}\right.$ $=0.09 ; p>0.70)$. This result suggests that the observed differences in behavior did not originate from differences in brain concentrations of cocaine.

\section{DISCUSSION}

Our results indicate that individual differences in cocaine selfadministration originate from vertical shifts in dose-response functions. These vertical shifts can be predicted on the basis of the behavioral reactivity of a subject to a stress challenge, i.e., the forced exposure to a novel environment. High responders to novelty compared with low responders show acquisition of cocaine self-administration at low cocaine doses and an upward shift in dose-response functions.

Classically (Kenakin, 1993), shifts in dose-response functions are described as changes in (1) "maximal response," the pharmacological term that describes the intensity of drug effects, and (2) "potency," the pharmacological term describing the location of the dose-response curve along the concentration axis. Changes in maximal response and potency are determined by various properties of the substrate or by factors relating more strictly to the drug-receptor interaction (Kenakin, 1993). The substraterelated factors are (1) the density of receptors for the drug, and (2) the "efficiency" of the substrate in converting receptor stimulus into tissue response. The factors belonging to the drugreceptor interaction are (1) the "intrinsic efficacy" of the drug, defined as the effect per unit of pharmacon-receptor complex, and (2) the "affinity" of the drug for the receptor. Clearly, in vivo, the bioavailability of the drug also plays an important role. The possibility to infer some of these variables, such as efficacy, from in vivo dose-response function has been questioned (Colquhoun, 1998). However, the conceptual frame outlined above represents the most common approaches in interpreting pharmacological data. For these reasons, it will be used here to interpret the shift in the observed dose-response functions.

It may seem straightforward to say that vertical shifts in cocaine dose-response functions originate from variations in the maximal response to cocaine because this is the variable that describes vertical shifts in dose-response functions (Kenakin, 1993). However, self-administration dose-response functions do not provide a typical measure of maximal response. The maximal response is normally considered as the response that is obtained at doses that approximate the $\mathrm{ED}_{100}$, whereas the highest rate of responding in self-administration is obtained at doses that approximate the $\mathrm{ED}_{50}$. Despite this particularity of self-administration doseresponse functions, several observations suggest that vertical shifts originate from changes in the maximal response to the drug. First, the ratio-response experiment was performed using an $\mathrm{ED}_{100}$ dose. In this condition, the reinforcing effects of cocaine were found to be higher in individuals showing an upward shift in dose-response function. This result is compatible only with an increase in the maximal response to cocaine, otherwise no differences should have been found using an $\mathrm{ED}_{100}$ dose. Second, in the context of our experiments, an increase in the maximal response to cocaine should originate from an increase in the value of the substrate-related factors. Intrinsic efficacy can be excluded because cocaine is a constant in these experiments. Differences between HRs and LRs in the activity of the dopaminergic projections into the nucleus accumbens, one of the principal substrates of cocaine-reinforcing effects (Piazza and Le Moal, 1996; Wise, 1996; Koob and Le Moal 1997), fulfill this prediction. Dopamine release in the accumbens, in basal conditions (Hooks et al., 1991; Piazza et al., 1991b), after stress (Rougé-Pont et al., 1993), and after an injection of cocaine (Hooks et al., 1991), is higher in HRs (upward shifted) than in LRs (downward shifted). Furthermore, HRs and LRs also differ for other neurotransmit- 
ters that regulate dopamine release (Lucas et al., 1998). Finally, the number of dopaminergic receptors in the accumbens also differs between the two groups (Hooks et al., 1994), and HRs show a higher response to the direct infusion of dopamine in this structure (Hooks et al., 1994).

Three lines of observations suggest that it is unlikely that vertical shifts in cocaine self-administration dose-response functions involve a selective change in potency. First, changes in potency induce selectively horizontal shifts in dose-response functions, i.e., similar to the ones depicted in Figure $1 B$, a phenomenon that has not been observed here. Second, in the case of a selective change in potency, differences in the effect of the drug should disappear at the $\mathrm{ED}_{100}$ (Kenakin, 1993). In contrast, in the progressive ratio experiments, large differences between $\mathrm{HI}$ and LI were found at this dose. Third, at the biological level, variations in potency should correspond to individual differences in the affinity of the receptor, in this case probably the dopamine transporter (Ritz et al., 1987), or in the bioavailability of the drug (Kenakin, 1993). In fact, these two factors did not differ in HRs and LRs (current paper and Hooks et al., 1994); nevertheless, cocaine dose-response functions were upward and downward shifted, respectively, in these animals.

The results of the self-administration acquisition study comparing HR and LR animals indicate that an upward shift in the dose-response function for cocaine self-administration is associated with a lower threshold dose for acquiring this behavior. This result may seems surprising because a decrease in the threshold dose indicates a higher sensitivity to the drug that is usually considered as a consequence of an increase in potency. In fact, in the case of vertical shifts in dose-response functions, changes in the threshold dose can be observed without an accompanying increase in potency (Kenakin, 1993). Consequently, it is not necessary to appeal to a change in potency to explain changes in the threshold dose. However, although the present experiments do not suggest that changes in potency are a major determinant of individual differences in self-administration, it would not be surprising that in other circumstances a higher maximal response to the drug may be accompanied by an increase in potency. Thus, a selective increase in intrinsic efficacy or in the efficiency of the substrate to translate the effects of the drug, the two factors determining an increase in maximal response, can also induce a decrease in the $\mathrm{ED}_{50}$ of the drug, i.e., an increase in potency. In this case, dose-response functions would be both upward and leftward shifted, suggesting an even more vulnerable phenotype that is still consistent with the model presented in Figure $1 C$.

The results presented in this report clearly characterize individual differences in cocaine self-administration. It appears that some more vulnerable subjects (1) acquire self-administration at low cocaine doses, (2) provide a higher rate of responding and intake higher quantities of the drug across doses, and (3) are ready to provide a higher amount of work to obtain the drug. This behavioral profile seems principally determined by a higher maximal response to cocaine that may results from a higher activity of the substrates translating the response to the drug, probably the mesencephalic dopaminergic transmission. For these reasons, also in an environmental condition in which high drug doses are encountered, such as the real world, these individuals will be more vulnerable to drug abuse. They will develop the highest rate of drug self-administration and be ready to provide more work to obtain the drug. Furthermore, because these individuals take the highest drug quantities, they will also have the highest chances to develop the drug-induced adaptations that contribute to drug dependence (Robinson and Berridge, 1993; Stewart and Badiani, 1993; Hyman and Nestler, 1996; Koob and Le Moal, 1997).

The focus of the present report is on individual differences; however, its results and interpretations also contribute to the understanding of vulnerability to drugs in a more general way. Indeed, upward shifts in dose-response functions have been observed as a consequence of the repeated exposure to stress (Carrol and Meich, 1984; Miczek and Mutscheler, 1996) or to drugs of abuse (Schenk and Partridge, 1997; Deroche et al., 1999), two conditions considered major etiological factors of addiction (Kalivas and Stewart, 1991; Robinson and Berridge, 1993; Piazza and Le Moal, 1998). Furthermore, in all of these cases, a decrease in the threshold dose for self-administration (Piazza et al., 1990; Haney et al., 1995; Vezina et al., 1999) and an increased performance in progressive ratio schedules (Shaham and Stewart, 1994; Lorrain et al., 2000) have been also reported. Finally, in the case of stress and of the repeated exposure to drugs, an increase in the functional activity of the substrates translating the effects of drugs of abuse, such as the dopaminergic projection to the nucleus accumbens, has also been found (Kalivas and Stewart, 1991; Robinson and Berridge, 1993; Piazza and Le Moal, 1998; Vezina et al., 1999). Alas, an increase in the maximal response to drugs of abuse determining an upward shift in the dose-response function seems to be a phenomenon not restricted to individual differences but a general phenotype describing vulnerability to drugs.

These observations suggest that potential therapies of addiction should be designed to decrease the maximal response to drugs of abuse. In this respect, pharmacological manipulations of glucocorticoid hormones could be a good target because they induce changes consistent with a reduction in the maximal response to cocaine. At the neurochemical level, suppression of the secretion of glucocorticoids (Piazza et al., 1996b) or administration of glucocorticoid receptor antagonists (Marinelli et al., 1998) induces a decrease in basal and drug-induced dopamine release. At the behavioral level, suppression of glucocorticoid secretion reduces cocaine intake (Piazza et al., 1994), inducing profound vertical shifts in the dose-response functions for cocaine-induced self-administration (Deroche et al., 1997) and locomotion (Marinelli et al., 1997). The potential interest of pharmacological manipulations of glucocorticoid hormones is strengthened by the pathophysiological link that seems to exist between these hormones and vulnerability to drug abuse. Thus, glucocorticoids seems to mediate the higher dopaminergic and behavioral responses to cocaine observed in both HRs (Piazza et al., 1991a,b) and stressed subjects (Rougé-Pont et al., 1995; Piazza and Le Moal, 1996).

In conclusion, these results demonstrate the existence of a drug-vulnerable phenotype relevant for the etiology of addiction and provide a framework for further studying its biological determinants. The challenge for the future will be to elucidate the molecular basis for this phenotype to design more selective therapies of addiction.

\section{REFERENCES}

Altman J, Everitt BJ, Glautier S, Markou A, Nutt D, Oretti R, Phillips GD, Robbins TW (1996) The biological, social and clinical bases of drug addiction: commentary and debate. Psychopharmacology $125: 285-345$.

Carrol ME, Meich RA (1984) Increased drug-reinforced behavior due to food deprivation. Adv Behav Pharmacol 4:47-88.

Colquhoun D (1998) Binding, gating, affinity and efficacy: the interpre- 
tation of structure-activity relationships for agonists and of the effects of mutating receptors. Br J Pharmacol 125:924-947.

Crabbe JC, Belknap JK, Buck KJ (1994) Genetic animal models of alcohol and drug abuse. Science 264:1715-1723.

Crowley TJ, Mikulich SK, MacDonald M, Young SE, Zerbe GO (1998) Substance-dependent, conduct-disordered adolescent males: severity of diagnosis predicts 2-year outcome. Drug Alcohol Depend 49:225-237.

De Wit H, Uhlenhuth EH, Johanson CE (1986) Individual differences in the reinforcing and subjective effects of amphetamine and diazepam. Drug Alcohol Depend 16:341-360.

Deminière JM, Piazza PV, Le Moal M, Simon H (1989) Experimental approach to individual vulnerability to psychostimulant addiction. Neurosci Biobehav Rev 13:141-147.

Deroche V, Marinelli M, Le Moal M, Piazza PV (1997) Glucocorticoids and behavioral effects of psychostimulants. II. Cocaine intravenous self-administration and reinstatement depend on glucocorticoid levels. J Pharmacol Exp Ther 281:1401-1407.

Deroche V, Le Moal M, Piazza PV (1999) Cocaine self-administration increases the incentive motivational properties of the drug in rats. Eur J Neurosci 11:2731-2736.

Haney M, Maccari R, Le Moal M, Simon H, Piazza PV (1995) Social stress increases the acquisition of cocaine self-administration in male and female rats. Brain Res 698:46-52.

Hooks MS, Jones GH, Smith AD, Neill DB, Justice Jr JB (1991) Response to novelty predicts the locomotor and nucleus accumbens dopamine response to cocaine. Synapse 9:121-128.

Hooks MS, Juncos JL, Justice Jr JB, Meiergerd SM, Povlock SL, Schenk JO, Kalivas PW (1994) Individual locomotor response to novelty predicts selective alterations in D1 and D2 receptors and mRNAs. J Neurosci 14:6144-6152.

Hyman SE, Nestler EJ (1996) Initiation and adaptation: a paradigm for understanding psychotropic drug action. Am J Psychiatry 153:151-162.

Kalivas PW, Stewart J (1991) Dopamine transmission in the initiation and expression of drug- and stress-induced sensitization of motor activity. Brain Res Rev 16:223-244.

Kenakin T (1993) Pharmacological analysis of drug-receptor interaction. New York: Raven.

Koob GF, Le Moal M (1997) Drug abuse: hedonic homeostatic dysregulation. Science 278:52-58.

Koob GF, Vaccarino FJ, Amalric M, Bloom FE (1986) Neurochemical substrates for opiate reinforcement. Natl Inst Drug Abuse Res Monogr 71:146-164.

Lorrain DS, Arnold GM, Vezina P (2000) Previous exposure to amphetamine increases incentive to obtain the drug: long-lasting effects revealed by the progressive ratio schedule. Behav Brain Res 107:9-19.

Lucas LR, Angulo JA, Le Moal M, Mc Ewen BS, Piazza PV (1998) Neurochemical characterization of individual vulnerability to addictive drugs in rats. Eur J Neurosci 10:3153-3163.

Marinelli M, Rougé-Pont F, Deroche V, Barrot M, De Jesus-Oliveira C, Le Moal M, Piazza PV (1997) Glucocorticoids and behavioral effects of psychostimulants. I. Locomotor response to cocaine depends on basal levels of glucocorticoids. J Pharmacol Exp Ther 281:1392-1400.

Marinelli M, Aouizerate B, Barrot M, Le Moal M, Piazza PV (1998) Dopamine-dependent responses to morphine depend on glucocorticoid receptors. Proc Natl Acad Sci USA 95:7742-7747.

Miczek KA, Mutscheler NH (1996) Activational effects of social stress on iv cocaine self-administration in rats. Psychopharmacology 128:256-264.

O’Brien CP, Ehrman RN, Terns JN (1986) Classical conditioning in human opioid dependence. In: Behavioral analysis of drug dependence (Goldeberg SR, Stolerman IP, eds), pp 329-335. New York: Academic.

Piazza PV, Le Moal M (1996) Pathophysiological basis of vulnerability to drug abuse: role of an interaction between stress, glucocorticoids, and dopaminergic neurons. Ann Rev Pharmacol Toxicol 36:359-378.

Piazza PV, Le Moal M (1998) The role of stress in drug selfadministration. Trends Pharmacol 19:67-74.

Piazza PV, Deminière JM, Le Moal M, Simon H (1989) Factors that predict individual vulnerability to amphetamine self-administration. Science 245:1511-1513.

Piazza PV, Deminière JM, Le Moal M, Simon H (1990) Stress- and pharmacologically- induced behavioral sensitization increases vulnerability to acquisition of amphetamine self-administration. Brain Res 514:22-26.

Piazza PV, Maccari S, Deminière JM, Le Moal M, Mormède P, Simon H (1991a) Corticosterone levels determine individual vulnerability to amphetamine self-administration. Proc Natl Acad Sci USA 88:2088-2092.

Piazza PV, Rougé-Pont F, Deminière JM, Kharoubi M, Le Moal M, Simon H (1991b) Dopaminergic activity is reduced in the prefrontal cortex and increased in the nucleus accumbens of rats predisposed to develop amphetamine self-administration. Brain Res 567:169-174.

Piazza PV, Marinelli M, Jodogne C, Deroche V, Rougé-Pont F, Maccari S, Le Moal M, Simon H (1994) Inhibition of corticosterone synthesis by Metyrapone decreases cocaine-induced locomotion and relapse of cocaine self-administration. Brain Res 658:259-264.

Piazza PV, Rougé-Pont F, Deroche V, Maccari S, Le Moal M, Simon H (1996a) Glucocorticoids have state-dependent stimulant effects on the mesencephalic dopaminergic transmission. Proc Natl Acad Sci USA 93:8716-8720.

Piazza PV, Barrot M, Rougé-Pont F, Marinelli M, Maccari S, Abrous N, Simon H, Le Moal M (1996b) Suppression of glucocorticoid secretion and antipsychotic drugs have similar effects on the mesolimbic dopaminergic transmission. Proc Natl Acad Sci USA 93:15445-15450.

Ritz MC, Lamb RJ, Goldeberg SR, Kuhar MJ (1987) Cocaine receptors on dopamine transporters are related to self-administration of cocaine. Science 237:1219-1223.

Robinson TE, Berridge KC (1993) The neural basis of drug craving: an incentive-sensitization theory of addiction. Brain Res Rev 18:247-291.

Rougé-Pont F, Piazza PV, Kharouby M, Le Moal M, Simon H (1993) Higher and longer stress-induced increase in dopamine concentrations in the nucleus accumbens of animals predisposed to amphetamine self-administration. A microdialysis study. Brain Res 602:169-174.

Rougé-Pont F, Marinelli M, Le Moal M, Simon H, Piazza PV (1995) Stress-induced sensitization and glucocorticoids. II. Sensitization of the increase in extracellular dopamine induced by cocaine depends on stress-induced corticosterone secretion. J Neurosci 15:7189-7195.

Schenk S, Partridge B (1997) Sensitization and tolerance in psychostimulant self-administration. Pharmacol Biochem Behav 57:543-550.

Shaham Y, Stewart J (1994) Exposure to mild stress enhances the reinforcing efficacy of intravenous heroine self-administration in rats. Psychopharmacology 114:523-527.

Stewart J, Badiani A (1993) Tolerance and sensitization to the behavioral effects of drugs. Behav Pharmacol 4:289-312.

Vezina P, Pierre PJ, Lorrain DS (1999) The effect of previous exposure to amphetamine on drug-induced locomotion and self-administration of a low dose of the drug. Psychopharmacology 147:125-134.

Wise RA (1996) Neurobiology of addiction. Curr Opin Neurobiol 6:243-251. 